\title{
Metaplastic Protein Phosphatases
}

\author{
Eric Klann \\ Department of Molecular Physiology \& Biophysics and Division of Neuroscience, Baylor College of Medicine, Houston, Texas, 77030, USA
}

Activity-dependent synaptic plasticity is widely considered to be one of the cellular mechanisms that underlie learning and memory. Long-term potentiation (LTP) is the most intensely studied form of synaptic plasticity, in part because it can be induced at glutamatergic synapses in the mammalian brain, including the hippocampus, a structure known for its involvement in memory function. LTP can be divided into at least two phases, an early phase (E-LTP) and a late phase (L-LTP). There is a great deal known about the biochemical signal transduction cascades that underlie both E-LTP and L-LTP. However, comparatively little is known about the mechanisms by which prior activity may modulate synaptic plasticity, a phenomenon termed metaplasticity (Abraham and Bear 1996). In addition, it is not known whether there are differences in the metaplasticity of E-LTP and L-LTP. In this issue of Learning \& Memory, Woo and Nguyen (2002) present the results of an elegant series of experiments that begin to address these questions.

E-LTP is typically induced with one train of highfrequency stimulation (HFS) of $100 \mathrm{~Hz}$ and lasts 1-3 h, whereas L-LTP can be induced with multiple, spaced trains of $100 \mathrm{~Hz}$ HFS and persists for at least $24 \mathrm{~h}$ (for reviews, see Huang et al. 1996; Kandel 2001). The biochemical mechanisms supporting E-LTP and L-LTP have been extensively characterized. In hippocampal area CA1, both E-LTP and L-LTP are dependent on N-methyl-D-aspartate (NMDA) receptor activation, calcium influx into the postsynaptic neuron, and the activation of a number of protein kinase cascades. However, E-LTP and L-LTP can be distinguished from one another by several important criteria. The expression of L-LTP, but not E-LTP, requires activation of a cAMP-dependent protein kinase (PKA)/extracellular signal-regulated kinase (ERK) signaling cascade, transcription, and new protein synthesis (Huang et al. 1996; Kandel 2001). The delineation of the molecular mechanisms necessary for L-LTP has generated much excitement because very similar mechanisms appear to be necessary for the long-term storage of implicit memories (Kandel 2001). Metaplasticity is neither appreciated nor studied as intensely as LTP, but several forms of metaplasticity have been identified and described. For example, the induction of long-term depression (LTD) can be facilitated by previous periods of HFS (Christie and Abraham 1992), and the induction of LTP can be inhibited

E-MAIL eklann@bcm.tmc.edu; FAX (713) 798-3475.

Article and publication are at http://www.learnmem.org/cgi/doi/ $10.1101 / \mathrm{lm} .52802$. by previous periods of low-frequency stimulation (LFS; Christie and Abraham 1992; Huang et al. 1992). However, little is known about the biochemical signal transduction mechanisms that are involved in these forms of metaplasticity.

The first question Woo and Nguyen (2002) addressed was whether an LFS protocol $(5 \mathrm{~Hz}$ for $3 \mathrm{~min}$ ), which had no effect on naive synapses, could affect subsequently induced E-LTP and L-LTP. To address this question, they delivered LFS, waited $7 \mathrm{~min}$, and then induced either E-LTP or L-LTP. They observed that prior LFS had no effect on subsequently induced E-LTP. Surprisingly, they found that the same LFS protocol was able to completely block the expression of L-LTP. The inhibition of L-LTP by prior LFS was temporally limited because LFS could block subsequently induced L-LTP if the delay between LFS and the first train of HFS was $20 \mathrm{~min}$, but not if the delay was $40 \mathrm{~min}$. In addition, the authors also found that the LFS protocol could not reverse already established L-LTP. Taken together, these results indicate that prior synaptic activity differentially affects E-LTP and L-LTP and that the anterograde inhibition of L-LTP by prior synaptic activity is temporally restricted.

The second critical question that Woo and Nguyen (2002) addressed was the biochemical signaling mechanisms responsible for this novel form of metaplasticity. It was previously shown that LFS-induced LTD, paired-pulse stimulation-induced LTD in vivo, and depotentiation of LTP all require NMDA receptor activation and protein phosphatase 1 (PP1) and/or protein phosphatase 2A (PP2A) activity (Mulkey et al. 1993; O'Dell and Kandel 1994; Thiels et al. 2000). Therefore, they asked whether the anterograde inhibition of L-LTP by prior LFS required NMDA receptor activation and/or PP1/PP2A activity. The authors found that NMDA receptor blockade prevented LFS from inhibiting the subsequent induction of L-LTP. In addition, Woo and Nguyen found that both okadaic acid and calyculin A, inhibitors of PP1/PP2A, also prevented LFS from inhibiting the subsequent induction of L-LTP. Collectively, these findings indicate that NMDA receptor activation during LFS is required to trigger a signaling cascade that includes PP1/ PP2A, which can subsequently prevent the expression of L-LTP.

The findings of Woo and Nguyen indicate that protein phosphatases, which have been shown to play critical roles in the regulation of both LTP and LTD (Winder and Sweatt 2001), also play a critical role in a novel form of metaplas-

LEARNING \& MEMORY 9:153-155 @ 2002 by Cold Spring Harbor Laboratory Press ISSN1072-0502/02 \$5.00

$$
\begin{array}{llllllllllllllll} 
& E & A & R & N & I & N & G & \mathbf{Q} & M & E & M & O & R & Y \\
\text { www.learnmem.org } & & &
\end{array}
$$


ticity. An obvious question that arises from these findings is the identity of the molecules targeted by PP1/PP2A (Fig. 1). Because L-LTP is dependent on transcription that is coupled to a PKA/ERK signaling pathway, one intriguing target for protein phosphatases is cAMP-response element-binding protein (CREB). L-LTP was shown to be associated with enhanced CREB phosphorylation and stimulation of CREmediated gene expression (Impey et al. 1996). Although it is unknown whether LFS induces CREB dephosphorylation, a recent study has shown that LTD induced by paired-pulse stimulation in vivo is accompanied by the dephosphorylation of CREB (Thiels et al. 2002). The identity of the protein phosphatase responsible for the LTD-induced dephosphorylation of CREB was not determined, but it was shown previously that synaptic stimulation of cultured hippocampal neurons results in a PP1-dependent dephosphorylation of CREB (Bito et al. 1996). It remains to be determined whether the LFS protocol used by Woo and Nguyen can result in a PP1-dependent dephosphorylation of CREB and whether this is sufficient for the metaplastic inhibition of L-LTP they have described.

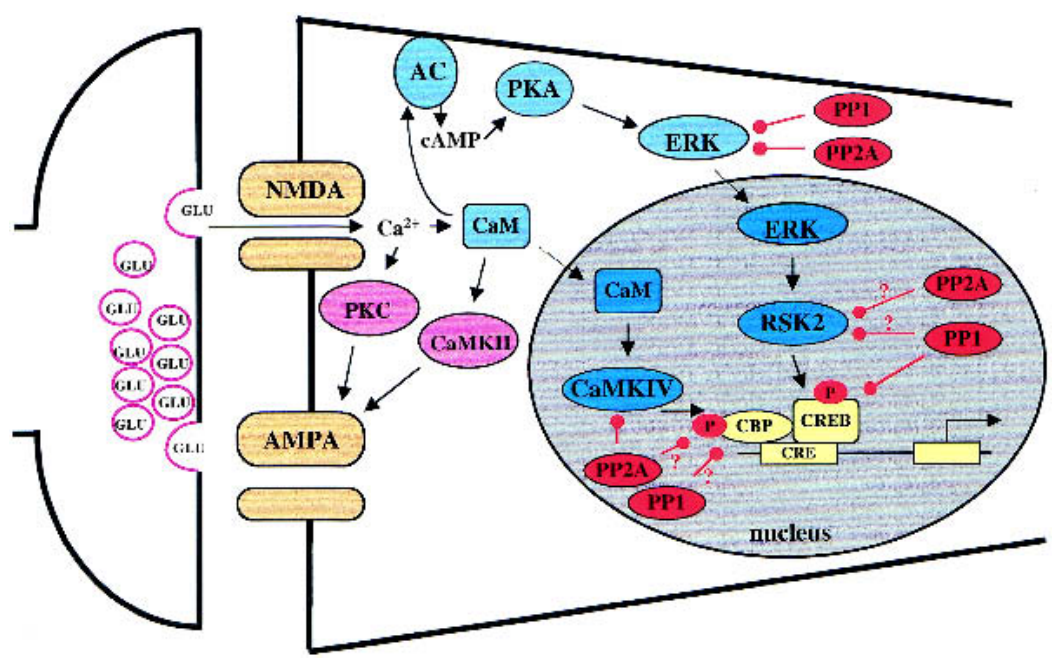

Figure 1 Possible targets for protein phosphatase-dependent metaplastic suppression of L-LTP. A single train of HFS results in E-LTP, whereas multiple trains of HFS result in L-LTP. E-LTP is dependent on NMDA receptor activation, calcium influx, and the activation of several protein kinases, including protein kinase $C$ (PKC) and calcium/ calmodulin-dependent protein kinase II (CaMKII). Similar to E-LTP, L-LTP is dependent on NMDA receptor activation, calcium influx, and the activation of additional protein kinase cascades. One well-characterized cascade associated with L-LTP includes the calcium/calmodulin-dependent activation of adenylyl cyclase (AC), production of CAMP, and activation of CAMP-dependent protein kinase (PKA). PKA then triggers the activation of an extracellular signal-regulated kinase (ERK) signaling cascade, resulting in nuclear translocation of ERK, phosphorylation and activation of ribosomal S6 protein kinase 2 (RSK2), phosphorylation of CREB, and CRE-mediated gene transcription. An additional protein kinase cascade that may be involved in L-LTP is calcium/calmodulindependent protein kinase IV (CaMKIV)-dependent phosphorylation and activation of the CREB activator CBP. Metaplastic suppression of L-LTP by prior LFS is dependent on protein phosphatase 1 (PP1) and/or protein phosphatase 2A (PP2A). Interactions of PP1/ PP2A with ERK, CREB, and CaMKIV have been observed previously, making them likely targets for PP1/PP2A-dependent suppression of L-LTP induced by prior LFS. Other possible targets that PP1/PP2A might act on to suppress L-LTP include RSK2 and CBP.
ERK is another target that PP1/PP2A could act on to contribute to the suppression of L-LTP by prior LFS. LTDwith a PP1/PP2A-dependent reduction in ERK immunoreshown that this type of LTD is associated with an increase in the phosphorylation of ERK at the dual phosphorylation site necessary for enzymatic activation of ERK (Thiels et al. 2002). Consistent with this observation, LTD was shown to activation of ERK resulted in the blockace of LTD (Thiels et al. 2002). Thus, ERK may be hanced ERK activation differs among LITP, LTD, or LFS does not produce LTD. Perhaps PP1/PP2A differentially regulates the duration and/or the magnitude of the increased activation of ERK depending on the pattern of synaptic activity. Alternatively, dephosphorylation of ERK outside of the dual phosphorylation site by PP1/PP2A might alter the subcellular localization of ERK, preventing it from translocating to the nucleus. These possibilities await further examination.

There are other possible targets for PP1/PP2A that could contribute to the metaplastic suppression of L-LTP by prior LFS. If ERK phosphorylation and activation is not altered, or is even increased with LFS, CREB dephosphorylation could still be achieved by direct dephosphorylation of CREB, as described above. Alternatively, CREB dephosphorylation could arise via the dephosphorylation and inactivation of ribosomal $\mathrm{S} 6$ protein kinase 2 , the likely intermediary kinase between ERK and CREB (Xing et al. 1996; Impey et al. 1998). Calcium/calmodulin-dependent kinase IV (CaMKIV) and the CREB coactivator CBP are two additional molecules involved in the CREB-dependent transcription machinery that might be regulated by PP1/PP2A after LFS. It was recently shown that NMDAinduced, CREB-dependent transcription is mediated by CaMKIV-dependent phosphorylation of CBP (Impey et al. 2002). Thus, LFS could result in the PP1/PP2A-induced dephosphorylation of either CaMKIV or CBP, thereby limiting transcription and resulting in the metaplastic suppression of L-LTP. Consistent with this possibility, PP2A has been shown to dephosphorylate and negatively regulate CaMKIV (Westphal et al.

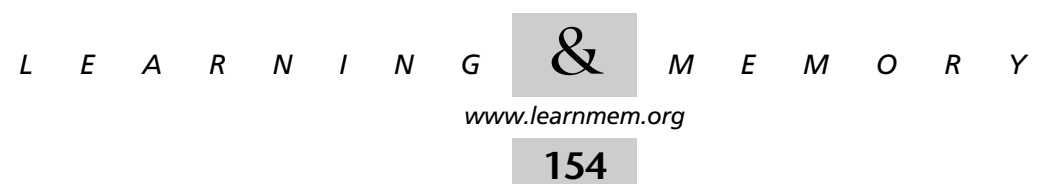


1998). Finally, in addition to transcription, L-LTP also requires new protein synthesis (Kandel 2001). Therefore, it is possible that LFS-induced activation of PP1/PP2A could result in the dephosphorylation of any number of protein translation factors that are necessary for L-LTP. However, the regulation of the phosphorylation of protein translation factors during either L-LTP or after LFS in the hippocampus is unknown at this time.

The similarities in the biochemical signal transduction cascades that are involved in hippocampal L-LTP and hippocampus-dependent memory make it tempting to speculate that the protein phosphatase-dependent metaplasticity of L-LTP described by Woo and Nguyen (2002) might underlie certain types of experience-dependent impairments in long-term memory formation. For example, hippocampal LTP and hippocampus-dependent memory have been shown to be impaired by stress, in part via activation of neuromodulatory signaling pathways involving corticosterone, serotonin, opiates, and corticotropin-releasing factor (Kim and Diamond 2002). The determination of the role of protein phosphatases in these stress-induced neuromodulatory signaling pathways, and whether protein phosphatases play a role in experience-dependent impairments in either L-LTP or hippocampus-dependent memory are exciting questions that await further attention.

\section{REFERENCES}

Abraham, W.C. and Bear, M.F. 1996. Metaplasticity: The plasticity of synaptic plasticity. Trends Neurosci. 19: 126-130.

Bito, H., Deisseroth, K., and Tsein, R.W. 1996. CREB phosphorylation and dephosphorylation: A $\mathrm{Ca}^{2+}$ - and stimulus duration-dependent switch for hippocampal gene expression. Cell 87: 1203-1214.

Christie, B.R. and Abraham, W.C. 1992. Priming of associative long-term depression in the dentate gyrus by $\theta$ frequency synaptic activity. Neuron 9: 79-84.

English, J.D. and Sweatt, J.D. 1997. A requirement for the mitogen-activated protein kinase cascade in hippocampal long term potentiation. J. Biol. Chem. 272: 19103-19106.

Huang, Y.Y., Colino, A., Selig, D.K., and Malenka, R.C. 1992. The influence of prior synaptic activity on the induction of long-term potentiation. Science 255: 730-733.

Huang, Y.Y., Nguyen, P.V., Abel, T., and Kandel, E.R. 1996. Long-lasting forms of synaptic potentiation in the mammalian hippocampus. Learn. Mem. 3: 74-85.

Impey, S., Mark, M., Villacres, E.C., Poser, S., Chavkin, C., and Storm, D.R. 1996. Induction of CRE-mediated gene expression by stimuli that generate long-lasting LTP in area CA1 of the hippocampus. Neuron 16: $973-982$.

Impey, S., Obrietan, K., Wong, S.T., Poser, S., Yano, S., Wayman, G., Deloulme, J.C., Chan, G., and Storm, D.L. 1998. Cross talk between ERK and PKA is required for $\mathrm{Ca}^{2+}$ stimulation of CREB-dependent transcription and ERK nuclear translocation. Neuron 21: 869-883

Impey, S., Fong, A.L., Wang, Y., Cardinaux, J.R., Fass, D.M., Obrietan, K., Wayman, G.A., Storm, D.R., Soderling, T.R., and Goodman, R.H. 2002 Phosphorylation of CBP mediates transcriptional activation by neural activity and CaM kinase IV. Neuron 34: 235-244.

Kandel, E.R. 2001. The molecular biology of memory storage: A dialogue between genes and synapses. Science 294: 1030-1038.

Kim, J.J. and Diamond, D.M. 2002. The stressed hippocampus, synaptic plasticity and lost memories. Nat. Rev. Neurosci. 3: 453-462.

Mulkey, R.M., Herron, C.E., and Malenka, R.C. 1993. An essential role for protein phosphatases in hippocampal long-term depression. Science 261: 1051-1055

Norman, E.D., Thiels, E., Barrionuevo, G., and Klann, E. 2000. Long-term depression in the hippocampus in vivo is associated with protein phosphatase-dependent alterations in extracellular signal-regulated kinase. J. Neurochem. 74: 192-198.

O'Dell, T.J. and Kandel, E.R. 1994. Low-frequency stimulation erases LTP through an NMDA receptor-mediated activation of protein phosphatases. Learn. Mem. 1: 129-139.

Thiels, E., Kanterewicz, B.I., Knapp, L.T., Barrionuevo, G., and Klann, E. 2000. Protein phosphatase-mediated regulation of protein kinase $\mathrm{C}$ during long-term depression in the adult hippocampus in vivo. $J$. Neurosci. 20: 7199-7207.

Thiels, E., Kanterewicz, B.I., Norman, E.D., Trzaskos, J.T., and Klann, E. 2002. Long-term depression in the adult hippocampus in vivo involves activation of extracellular signal-regulated kinase and phosphorylation of Elk-1. J. Neurosci. 22: 2054-2062.

Westphal, R.S., Anderson, K.A., Means, A.R., and Wadzinski, B.E. 1998. A signaling complex of $\mathrm{Ca}^{2+}$-calmodulin-dependent protein kinase IV and protein phosphatase 2A. Science 280: 1258-1261.

Winder, D.G. and Sweatt, J.D. 2001. Roles of serine/threonine phosphatases in hippocampal synaptic plasticity. Nat. Rev. Neurosci. 2: 461-474.

Woo, N.H. and Nguyen, P.V. 2002. "Silent" metaplasticity of the late phase of long-term potentiation requires protein phosphatases. Learn. Mem. (this issue).

Xing, J., Ginty, D.D., and Greenberg, M.E. 1996. Coupling of the RAS-MAPK pathway to gene activation by RSK2, a growth factor-regulated CREB kinase. Science 273: 959-963. 


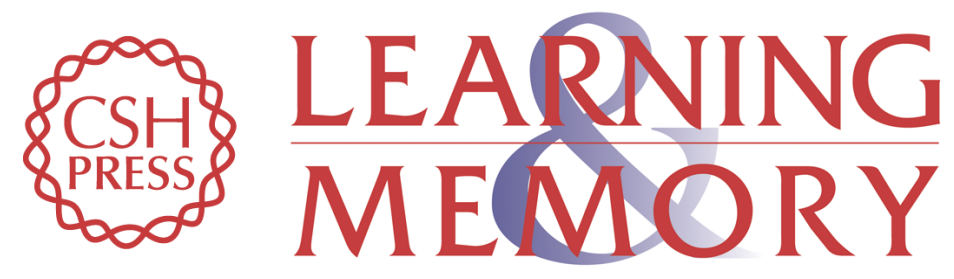

\section{Metaplastic Protein Phosphatases}

\section{Eric Klann}

Learn. Mem. 2002, 9:

Access the most recent version at doi:10.1101/lm.52802

References This article cites 19 articles, 10 of which can be accessed free at: http://learnmem.cshlp.org/content/9/4/153.full.html\#ref-list-1

License

Email Alerting Receive free email alerts when new articles cite this article - sign up in the box at the Service top right corner of the article or click here. 